\title{
Avaliações Quantitativas e Predição das Proporções de Osso, Músculo e Gordura da Carcaça em Ovinos
}

\author{
Lisiane Furtado da Silva ${ }^{1}$, Cleber Cassol Pires ${ }^{2}$
}

\begin{abstract}
RESUMO - O objetivo deste experimento foi estudar as características da carcaça e suas correlações com a composição tecidual. Foram utilizados 22 cordeiros machos inteiros, filhos de carneiros Texel e ovelhas cruzas (Texel x Ideal). Destes, quatro foram abatidos no início do experimento (24 horas após o nascimento), como referência, e o restante, ao desmame e aos 28 e 33 kg PV. Os cordeiros foram confinados em baias individuais com suas respectivas mães até o desmame (45 dias de idade). Nesse período, a dieta fornecida, constituída de $70 \%$ de volumoso e $30 \%$ de concentrado, visava atender às necessidades nutricionais da mãe. A partir do desmame até o abate, a dieta fornecida aos cordeiros foi constituída de $60 \%$ de volumoso e $40 \%$ de concentrado. Os rendimentos de carcaça fria foram 51,$20 ; 45,14 ; 42,216 ;$ e 41,73\% para os pesos de abate de 20,93; 28,3;32,57; e 4,12 kg PV, respectivamente. A relação tecido mole/osso foi de 1,74 e 4,24\%, respectivamente, para os cordeiros abatidos ao nascimento e os abatidos com 32,57 kg. Os maiores coeficientes de determinação e correlação foram obtidos para a equação da porcentagem de músculo da carcaça, em função da proporção do mesmo na costela. Os valores dos coeficientes de determinação e correlação foram, respectivamente, 71,65 e 0,85 . Para as equações das porcentagens de osso e gordura na carcaça, os maiores coeficientes de determinação foram obtidos para costela.
\end{abstract}

Palavras-chave: carcaça, composição tecidual, cordeiro, ovino, produção de carne

\section{Quantitative Evaluation and Prediction of the Bone, Muscle and Fat Proportion of the Ovine Carcass}

\begin{abstract}
The objective of this experiment was to study the carcass traits and their correlation with the tissue composition. Twenty-two intact male lambs, sired by Texel males, from crossbreed Texel-Ideal dams were used. At the beginning of the experiment ( 24 hours after birth), four lambs were slaughtered to serve as reference and a group of six lambs were slaughtered at weaning time and at 28 and $33 \mathrm{~kg} \mathrm{LW}$. The lambs were confined in individual stall with their respective mothers until weaning time ( $45 \mathrm{days}$ of age). In that time, the diet was fed to supply the nutritional requirement of the dams and was constituted of 70: 30 forage to concentrate ratio. From the weaning until the slaughter time, the diet fed to the lambs was constituted by 60:40 forage to concentrate ratio. The cold carcass yield were $51.20,45.14,42.26$ and $41.73 \%$, respectively, for the slaughtered weight of $20.93,28.3,32.57$ and $4.12 \mathrm{~kg} \mathrm{LW}$. The soft tissue/ bone relation was of 1.74 and 4.24 , respectively, for lambs slaughtered at birth and at $32.57 \mathrm{~kg} \mathrm{LW}$. The highest coefficients of determination and correlation were obtained for the carcass muscle percentage on the same tissue proportions in the rib. The coefficients of determination and correlation were, respectively, 71.65 and 0.85 . For the percentage of bone and fat equations in the carcass, the highest coefficients of determination were obtained on the same tissues proportions in the rib.
\end{abstract}

Key Words: carcass, lamb, meat production, sheep, tissue composition

\section{Introdução}

No sistema de produção de carne, as características quantitativas e qualitativas da carcaça são de fundamental importância, pois estão diretamente relacionadas ao produto final carne. O peso da carcaça, bem como suas características, é influenciado pela raça, pelo peso de abate, sexo, pela idade, entre outros fatores. O peso ideal de abate é determinado pelo mercado consumidor, sendo a quantidade de gordura na carcaça o ponto de referência. MÜLLER (1980) ressaltou que, de modo geral, carcaças prove- nientes de animais jovens apresentam carne de melhor qualidade que animais de mais idade. Segundo PÉREZ et al. (1998), a maior parte da carne ovina ofertada no Brasil é proveniente de animais que têm baixa qualidade de carcaça. Esta qualidade está relacionada, fundamentalmente, a diversos fatores relativos ao animal, ao meio, à nutrição, entre outros, havendo, ainda, fatores relativos à carcaça propriamente dita, como comprimento do corpo, comprimento da perna, quantidade de gordura de cobertura, entre outros.

Segundo OSÓRIO et al. (1998), como consequiência dos distintos sistemas de produção e de suas raças, o

\footnotetext{
1 Zootecnista, Mestre.

2 Professor do Departamento de Zootecnia da UFSM. E.mail: cpires@ccr.ufsm.br
} 
mercado da carne ovina apresenta grande variabilidade dos caracteres quantitativos e qualitativo que definem os diferentes tipos de carcaças comercializadas. Esta variabilidade não constitui inconveniente para a comercialização, por oferecer ao mercado carcaças diferentes, que podem satisfazer às mais variadas preferências da demanda. Trabalhos realizados com ovinos mostram que o peso de carcaça fria de cordeiros abatidos com 20,25 a 35,07 $\mathrm{kg}$ de peso corporal variou de 7,90 a $15,55 \mathrm{~kg}$ e o rendimento de carcaça fria, de 38,86 a 47,97\% (COSTAÑER et al., 1992; SILVA et al., 1994; OSÓRIO et al., 1996; CARVALHO, 1998; GARCIA et al., 1998; OSÓRIO et al., 1999; e PIRES et al., 1999).

As medidas realizadas na carcaça são importantes por si próprias, pois permitem comparações entre tipos raciais, pesos e idades de abate, sistemas de alimentação, e também pela suas correlações com outras medidas ou com os tecidos constituintes da carcaça, possibilitando a estimação de suas características físicas, evitando, dessa forma, o oneroso processo de dissecação de carcaça.

JORGE et al. (1999) relatou que a estimativa das características da carcaça é de suma importância para complementar a avaliação do desempenho do animal durante seu desenvolvimento.

Este trabalho realizou-se com o objetivo de comparar as características de carcaça de cordeiros abatidos com diferentes idades e suas correlações com as proporções de tecidos.

\section{Material e Métodos}

O experimento foi conduzido no Setor de Ovinocultura do Departamento de Zootecnia da Universidade Federal de Santa Maria (UFSM). Foram utilizados 22 cordeiros machos inteiros, filhos de carneiros Texel e ovelhas cruzas (Texel x Ideal). Destes, quatro foram abatidos nas primeiras 24 horas de vida (abate inicial) e os remanescentes, distribuídos juntamente com suas mães nos outros tratamentos, constituídos por abates ao desmame (PD), aos $28 \mathrm{~kg}\left(\mathrm{P}_{28}\right)$ e aos $33 \mathrm{~kg}\left(\mathrm{P}_{33}\right)$ de peso vivo. Permaneceram com as mães em baias individuais com área de $4 \mathrm{~m}^{2}$ até o desmame (45 dias de idade).

Durante o período experimental, foram utilizadas duas dietas, sendo a primeira do nascimento ao desmame, visando atender às exigências nutricionais da ovelha lactante. A segunda, do desmame ao abate, visava atender às necessidades nutricionais dos cordeiros. Ambas foram calculadas de acordo com o
NATIONAL RESEARCH COUNCIL - NRC (1985), sendo a primeira para as primeiras seis semanas de lactação de ovelhas com $50 \mathrm{~kg}$ de peso vivo e nascimento simples; e a segunda, para cordeiros em crescimento, pesando $20 \mathrm{~kg}$ de peso corporal e com ganho de peso de $300 \mathrm{~g} /$ dia. A relação volumoso:concentrado utilizada foi de 70:30 para a primeira dieta e 60:40 para a segunda. Trabalhou-se com silagem de milho e concentrado composto por farelo de soja, milho e mistura mineral.

Os cordeiros foram pesados com jejum de sólidos de doze horas e, imediatamente, sacrificados. O peso de corpo vazio (PCV) foi obtido por meio da diferença entre peso de abate (PA) e conteúdo gastrintestinal.

Foi obtido o peso de carcaça quente (PCQ) e, após seu resfriamento, em câmara frigorífica, a $2^{\circ} \mathrm{C}$ por 24 horas, o peso de carcaça fria (PCF). Foram determinados o rendimento de carcaça quente $(\mathrm{RCQ})=$ (PCQ/PA)x100, o rendimento de carcaça fria $(\mathrm{RCF})=(\mathrm{PCF} / \mathrm{PA}) \times 100$ e o rendimento verdadeiro $(\mathrm{RV})=(\mathrm{PCF} / \mathrm{PCV}) \times 100$. De acordo com MÜLLER (1980), foi medida a área do músculo Longissimus dorsi (área de olho de lombo) entre a $12^{\mathrm{a}}$ e $13^{\mathrm{a}}$ costelas, traçando-se o contorno do músculo em papel vegetal, para posterior determinação da área por meio do programa computacional Sistema de Informações Territoriais Rurais (Departamento de Engenharia Agrícola da UFSM). Obteve-se também, no mesmo perfil, a espessura de gordura de cobertura (EG).

A carcaça foi dividida ao meio, e na metade direita foram tomadas as seguintes medidas: comprimento de carcaça (CC): distância entre o bordo anterior da sínfise ísquio - pubiana e o bordo anterior da primeira costela em seu ponto médio; comprimento de perna (CP): distância entre o bordo anterior da sínfise ísquio - pubiana e a porção média dos ossos do tarso; perímetro de braço (PBR): medido na porção mediana do braço; e largura de perna (LP): distância entre os bordos interno e externo da parte superior da perna, em sua parte mais larga, realizada com compasso de madeira de pontas metálicas e aferida a distância em centímetros. A compacidade da carcaça (COM) foi obtida por meio da relação entre o peso vivo e o comprimento da carcaça, em $\mathrm{kg} / \mathrm{cm}$.

A separação do pescoço foi feita entre a $3^{\mathrm{a}}$ e a $4^{\mathrm{a}}$ vértebras cervicais. O costilhar foi obtido por meio de um corte tangente à coluna vertebral, ou seja, um corte de todas as ripas na articulação destas com as vértebras, de modo que o costilhar compreendeu todas as costelas, inclusive as que ficassem por baixo da paleta. A paleta foi seccionada, de modo que hou- 
vesse a liberação da escápula da costela, no nível da porção média dos ossos do carpo; o quarto, no nível da articulação da última vértebra lombar; e a primeira sacral no nível da região média dos ossos do tarso. O espinhaço constituiu-se das vértebras torácicas e lombares e músculo Longissimus dorsi, sendo obtido após a retirada do pescoço e costilhar direito e esquerdo. Cada corte da $1 / 2$ carcaça foi dissecado e as porções de osso, músculo e gordura, pesadas. A composição tecidual da carcaça foi estimada a partir das quantidades de osso, músculo e gordura do pescoço, quarto, espinhaço, costela e paleta da meia-carcaça.

Os dados foram submetidos à análise de variância, teste $\mathrm{F}$, estudos de regressão e correlações, e as médias, comparadas pelo teste de Pdiff, utilizando o programa estatístico SAS (SAS, 1990). Para os estudos de regressão e correlação, foram utilizados todos os animais, com exceção dos abatidos ao nascimento.

\section{Resultados e Discussão}

Na Tabela 1, são apresentados os valores médios para peso de carcaça quente (PCQ), peso de carcaça fria (PCF), quebra por resfriamento $(\mathrm{QR})$, rendimento de carcaça quente (RCQ), rendimento de carcaça fria (RCF) e rendimento verdadeiro (RV). Observase que houve diferença entre o peso vivo de 20,93 e os pesos de 28,30 e 32,57 kg para as variáveis PCQ, PCF, QR e RV. Os resultados médios dos três pesos, relativos ao PCQ $(12,74 \mathrm{~kg})$ e PCF $(12,42 \mathrm{~kg})$, foram semelhantes aos de OSÓRIO et al. (1996), os quais verificaram valores de 12,75 e 12,27 kg, respectivamente, para cordeiros da raça Texel abatidos com 225 dias de idade com pesos de 29,26 kg de peso vivo. Foram próximos ao PCQ de 13,35 kg e PCF de 12,92 kg, verificados por OSÓRIO et al. (1999), para cordeiros cruzas (Corriedale x Hampshire Down), abatidos com 30,63 kg aos 150 dias de idade. Levando-se em consideração os pesos de abate de 20,93; 28,30; e $32,57 \mathrm{~kg} \mathrm{e}$, principalmente, as idades médias correspondentes (45, 93 e 118 dias, respectivamente), verifica-se que houve maior eficiência na produção de carne no presente estudo, quando comparada aos resultados acima citados. Maior eficiência também em relação aos resultados observados por PIRES et al. (1999), que encontraram valores médios de $12,35 \mathrm{~kg}$ para PCQ e 12,03 kg para PCF, com cordeiros abatidos com $30,22 \mathrm{~kg}$, entre seis e sete meses de idade.

Verifica-se que os animais abatidos ao desmame $(20,93 \mathrm{~kg})$ apresentaram os maiores rendimentos
RCQ, RCF e RV, que começaram a diminuir a partir daí. Isto deve estar relacionado ao crescimento do trato gastrintestinal (TGI), que apresentou ritmo mais acelerado de crescimento após o desmame, pois, para o peso supra citado, o TGI representou $4,05 \%$ do $\mathrm{PCV}$, ao passo que, para os pesos de abate de 28,30 e $32,57 \mathrm{~kg}$, os percentuais foram de 7,95 e 9,94\% do PCV, respectivamente (SILVA, 1999). Considerando-se os pesos de abates de 28,30 e $32,57 \mathrm{~kg}$, os resultados são similares aos obtidos por MONTEIRO et al. (1998), os quais encontraram para cordeiros $3 / 4$ Suffolk + 1/4 sem raça definida, pesando $31,9 \mathrm{~kg}$, valores médios de $44,5 \%$ para RCQ, $43,0 \%$ para RCF e 51,9\% para RV. Estes resultados são semelhantes aos verificados por BUENO et al. (1998), que encontraram valores de $43,3 \%$ para $\mathrm{RCF}$ e de $50,9 \%$ para $\mathrm{RV}$, em cordeiros Suffolk abatidos com $31,8 \mathrm{~kg}$ de peso vivo (PV). Considerando-se que o rendimento de carcaça expressa a produção de carne, verifica-se que os cordeiros abatidos ao desmame, com 20,93 kg de peso vivo e 45 dias de idade, foram mais eficientes em relação àqueles abatidos com maior peso (Tabela 1) e aos dos trabalhos anteriormente citados.

Observa-se que ao QR diminuiu com o aumento do peso de abate. Em valores numéricos, os resultados são semelhantes aos observados por WYNN e THWAITES, 1981; OSÓRIO et al., 1996; GARCIA e SOBRINHO, 1998; MONTEIRO et al., 1998; CARVALHO, 1998; OSÓRIO et al., 1999; e SIQUEIRA e FERNANDES, 1999, cujos valores variaram de 2,48 a $7,6 \%$. O valor encontrado para os animais abatidos ao nascimento $(6,94 \%)$ deve ser decorrente da ausência de gordura na carcaça, o que permitiu grande enxugamento da mesma durante o resfriamento.

Os valores médios para as medidas realizadas na carcaça são apresentados na Tabela 2. Verifica-se que, para todas as medidas, com exceção da espessura de gordura (EG), os animais abatidos com maiores pesos apresentaram os maiores valores $(\mathrm{P}<0,05)$.

Com relação ao comprimento de carcaça (CC), os resultados para os pesos vivos de 28,30 e $32,57 \mathrm{~kg}$ foram superiores aos obtidos por OSÓRIO et al.(1996), os quais observaram valores de $52,7 \mathrm{~cm}$ para cordeiros da raça Texel abatidos com $29,6 \mathrm{~kg}$; no entanto, para compacidade da carcaça, os valores foram semelhantes. GARCIA et al. (1998) verificaram, para cordeiros machos inteiros da raça Santa Inês, abatidos com 25,90 kg de peso corporal, valores médios de 58,88 $\mathrm{cm}$ para comprimento de carcaça, enquanto BUENO et al. (1998) observaram média de $0,23 \mathrm{~kg} / \mathrm{cm}$ para compacidade da carcaça em cordeiros inteiros da raça 
Suffolk com 31,70 kg de peso vivo.

Quanto ao comprimento de perna (CP), os valores de 31,43 e 32,30 cm, observados neste experimento, para cordeiros abatidos com 28,30 e $32,57 \mathrm{~kg}$, foram inferiores aos verificados por OSÓRIO et al. (1996) e OSÓRIO et al. (1999), que encontraram valores de 50,7 e $51,08 \mathrm{~cm}$, para cordeiros abatidos com idade média de seis meses e pesos vivos de 29,26 e 30,63 kg, respectivamente, e superiores aos de GARCIA et al. (1998), os quais observaram $(21,61 \mathrm{~cm})$ para cordeiros da raça Santa Inês com $25,90 \mathrm{~kg}$ de peso vivo.

Com relação à largura de perna (LP) e perímetro de braço (PBR), constata-se que, do nascimento ao desmame $(20,93 \mathrm{~kg})$, essas medidas aumentaram 1,9 vezes, enquanto, do desmame ao peso de $32,57 \mathrm{~kg}$, a elevação foi de 1,2 vezes. Situação semelhante foi observada para o comprimento da carcaça, que do nascimento ao desmame aumentou $19,52 \mathrm{~cm}$; do desmame ao peso de $28,30 \mathrm{~kg}, 7,08 \mathrm{~cm}$; e deste peso ao de $32,57 \mathrm{~kg}$, apenas $1,58 \mathrm{~cm}$. Estes fatos, entre outros, mostram desaceleração no crescimento do animal, como um todo, com o aumento de seu peso, indicando que o abate de cordeiros com pesos muito elevados pode não ser a melhor opção.

Para a espessura de gordura (EG), observa-se que há tendência dos cordeiros abatidos com $32,57 \mathrm{~kg}$ apresentarem valores inferiores àqueles abatidos ao desmame $(20,93 \mathrm{~kg})$. Estes resultados são respaldados por SILVA (1999), que verificou para os mesmos animais, após dissecação da carcaça, proporções de gordura de $0 ; 21,18 ; 18,87$; e $15,45 \%$, para pesos de abates de 4,$12 ; 20,92 ; 28,30$; e $32,57 \mathrm{~kg}$, respectiva- mente. Essa maior EG para os animais abatidos ao desmame $(20,93 \mathrm{~kg})$ pode estar relacionada à alimentação dos cordeiros no período, que antecedeu ao desmame, pois, além de ingerirem o leite materno (24,7\% PB e 6,04 Mcal de energia bruta/kg de leite na MS, NRC, 1985), também se alimentavam da dieta fornecida à mãe, sendo que após o desmame a alimentação fornecida foi menos energética. De maneira geral, os resultados verificados para EG, neste trabalho (Tabela 2), são próximos aos verificados por BUENO et al. (1998), que obtiveram valores de 1,2 e 1,9 mm para machos inteiros e fêmeas da raça Suffolk, abatidos com peso médio de $31,7 \mathrm{~kg}$; CARVALHO (1998), que encontrou, para cordeiros abatidos aos 100 dias de idade e com peso médio de 27,09 kg, 1,78 mm de EG; e PÉREZ et al. (1998), os quais verificaram valores de 2,74 e 3,24 mm, para cordeiros das raças Santa Inês e Bergamácia abatidos com 53,43 e 52,86 kg de peso corporal, respectivamente. No entanto, foram superiores aos resultados obtidos por OSÓRIO et al. (1999), que observaram os valores de $0,5 \mathrm{~mm}$ para cordeiros machos castrados e $0,4 \mathrm{~mm}$ para machos inteiros, sacrificados com 27,53 e $30,63 \mathrm{~kg}$ de peso vivo, respectivamente.

Os resultados referentes à área de olho de lombo (AOL), nos pesos de 20,93; 28,30; e 32,57 kg, são inferiores aos de BUENO et al. (1998), que verificaram valores de 11,5 a $13,2 \mathrm{~cm}^{2}$, para cordeiros machos inteiros e fêmeas, respectivamente, abatidos com peso médio de $30,9 \mathrm{~kg}$. Os resultados para AOL (Tabela 2), para os pesos de 28,30 e 32,57 kg, foram semelhantes aos obtidos por CARVALHO (1998),

Tabela 2 - Médias das características quantitativas da carcaça de cordeiros Table 2 - Means of the quantitative carcass traits of lambs

\begin{tabular}{|c|c|c|c|c|c|c|c|}
\hline \multirow[t]{2}{*}{$\mathrm{PA}(S W), \mathrm{kg}$} & $\mathrm{PN}(B W)$ & $\mathrm{PD}(W W)$ & $\mathrm{P}_{28}\left(W_{28}\right)$ & $\mathrm{P}_{33}\left(W_{33}\right)$ & \multirow[t]{3}{*}{$\mathrm{F}$} & \multirow[t]{3}{*}{$\operatorname{Pr}>F$} & \multirow[t]{3}{*}{$\mathrm{CV} \%$} \\
\hline & 4,12 & 20,93 & 28,30 & 32,57 & & & \\
\hline $\mathrm{PCF}(C C W), \mathrm{kg}$ & 1,72 & 10,71 & 12,79 & 13,75 & & & \\
\hline $\mathrm{CC}(C L), \mathrm{cm}$ & $30,15^{\mathrm{c}}$ & $49,67^{b}$ & $56,75^{\mathrm{a}}$ & $58,33^{\mathrm{a}}$ & 222,19 & 0,0001 & 3,65 \\
\hline $\mathrm{CP}(L L), \mathrm{cm}$ & $21,67^{\mathrm{b}}$ & $30,77^{\mathrm{a}}$ & $31,43^{\mathrm{a}}$ & $32,30^{\mathrm{a}}$ & 50,37 & 0,0001 & 4,92 \\
\hline $\mathrm{LP}(L W), \mathrm{cm}$ & $3,80^{\mathrm{c}}$ & $8,25^{\mathrm{b}}$ & $9,58^{\mathrm{a}}$ & $10,25^{\mathrm{a}}$ & 39,70 & 0,0001 & 11,70 \\
\hline $\operatorname{PBR}(A P), \mathrm{cm}$ & $7,32^{\mathrm{c}}$ & $12,33^{b}$ & $13,60^{\mathrm{ab}}$ & $14,40^{\mathrm{a}}$ & 23,21 & 0,0001 & 11,20 \\
\hline $\mathrm{EG}(F T), \mathrm{mm}$ & - & $3,00^{\mathrm{a}}$ & $1,75^{\mathrm{ab}}$ & $1,42^{\mathrm{b}}$ & 3,47 & 0,0578 & 53,41 \\
\hline $\operatorname{COM}(L W / C L), \mathrm{kg} / \mathrm{cm}$ & $0,057^{\mathrm{c}}$ & $0,215^{b}$ & $0,225^{\mathrm{ab}}$ & $0,235^{\mathrm{a}}$ & 152,95 & 0,0001 & 7,33 \\
\hline $\operatorname{AOL}(L E A), \mathrm{cm}^{2}$ & $2,83^{\mathrm{b}}$ & $10,08^{\mathrm{a}}$ & $10,97^{\mathrm{a}}$ & $11,00^{\mathrm{a}}$ & 70,98 & 0,0001 & 10,62 \\
\hline
\end{tabular}

Médias, na linha, seguidas por letras diferentes são distintas $(\mathrm{P}<0,05)$ pelo teste Pdiff.

$\mathrm{PA}=\mathrm{Pes}$ de abate$; \mathrm{PCF}=\mathrm{Pes}$ de carcaça fria $\mathrm{CC}=$ Comprimento de carcaça; $\mathrm{CP}=$ Comprimento de perna $\mathrm{LP}=\mathrm{Largura}$ de perna; $\mathrm{PBR}=$ Perímetro de braço; $\mathrm{EG}=$ Espessura de gordura; $\mathrm{COM}=$ Compacidade da carcaça; $\mathrm{AOL}=\mathrm{A}$ rea de olho de lombo; $P N=P$ eso ao nascimento, $P D=P e s o$ ao desmame; $P_{28}=P e s o$ ao abate de $28 \mathrm{~kg} ; P_{33}=P e s o$ ao abate de $33 \mathrm{~kg}$. Means, within a row, followed by different letters are different $(P<.05)$ by Pdiff test.

$S W=$ Slaughter weight; $C C W=$ Cold carcass weight; $C L=$ Carcass lenght $L L=$ Leg lenght; $L W=$ Leg width; $A P=$ Arm perimeter; $F T=F a t$ thickness; $L W$ (Live weight)/CL (carcass lenght);LEA = Loin eye area.; $B W=B$ Birth; weight; $W W=$ Weaning weight; $W_{28}=$ Slaughter weight of $28 \mathrm{~kg} ; W_{33}=$ Slaughter weight of $33 \mathrm{~kg}$. 
que encontrou, para cordeiros machos inteiros, machos castrados e fêmeas, o valor médio de $11,28 \mathrm{~cm}^{2}$ de AOL. Também são próximos aos valores encontrados por OSÓRIO et al. (1999), que constataram valores para AOL de 10,2 e 11,99 $\mathrm{cm}^{2}$, para cordeiros machos castrados e inteiros, respectivamente.

As relações entre os tecidos que compõem a carcaça são apresentadas na Tabela 3. A relação músculo/osso (M/O) aumentou significativamente do nascimento ao desmame $(20,93 \mathrm{~kg})$, não tendo modificado a partir de então. Isto aconteceu porque o osso cresce mais rápido no início da vida dos cordeiros, sofrendo desaceleração à medida que o animal envelhece, ocorrendo o inverso com o músculo. A relação músculo/tecido adiposo (M/A) mostra que a gordura diminuiu com o aumento do peso vivo de 20,93 para $32,57 \mathrm{~kg}$, ou seja, no maior peso de abate existia menos gordura para determinada quantidade de músculo, portanto, os animais sacrificados ao desmame $(20,93 \mathrm{~kg})$ eram mais gordos que os demais. De acordo com BERG e BUTTERFIELD (1976), ao nascimento, os bovinos apresentam duas partes de músculo para uma parte de osso e, como o crescimento muscular é maior que o ósseo, no período pós-natal, a proporção de músculo em relação ao osso aumenta. Os mesmos autores chamam atenção que a porcentagem de tecido adiposo ao nascimento é muito pequena, mas, com alimentação adequada, o processo de deposição de gordura é bastante rápido. Esta afirmação corrobora os resultados do presente estudo, no qual os cordeiros ao desmame possuíam maior quantidade de gordura na carcaça, o que pode ser atribuído à participação do leite na alimentação do nascimento ao desmame, uma vez que CHIOU e JORDAN (1973), estudando a composição corporal de cordeiros alimentados com diferentes dietas, observaram que os animais alimentados exclusivamente com leite apresentaram $12,91 \%$ de gordura, enquanto outros alimentados com dieta sólida e diferentes níveis de proteína e energia apresentaram, em média, 9,9\% de gordura.

A relação tecido mole (músculo + gordura)/osso (TM/O) não diferiu entre os pesos mais elevados de abate, mas estes diferiram do peso ao nascimento (Tabela 3). JORGE et al. (1999), trabalhando com bovinos inteiros, observaram que a relação TM/O aumentou de 0,49 para 0,56 com a elevação do peso de abate de 405 para $500 \mathrm{~kg}$.

Os parâmetros das equações de predição da porcentagem de osso, músculo e gordura da carcaça, em função das proporções dos mesmos no quarto, paleta e costela, são apresentados na Tabela 4. Com base nos coeficientes de determinação obtidos para cada equação de predição, observa-se que a melhor estimativa da porcentagem de osso na carcaça foi obtida em função da porcentagem de osso da costela $\left(\mathrm{R}^{2}=93,16\right)$. Para a predição de músculo total da carcaça, a proporção de carne da costela foi a que apresentou o melhor coeficiente de determinação $\left(\mathrm{R}^{2}\right.$ $=71,65)$. Quanto às equações de predição da porcentagem de gordura na carcaça, verifica-se que o maior coeficiente de determinação $(79,89)$ foi obtido para a porcentagem de gordura da costela, seguida pela paleta $(76,31)$ e pelo quarto $(52,24)$. Os resultados deste trabalho são semelhantes aos obtidos por CARVALHO et al. (1998), que verificaram os melhores coeficientes de determinação para costela, no que se refere à predição da composição tecidual da carcaça. Os coeficientes encontrados pelos autores supra citados foram 48,77; 72,90; e 89,72 para osso, músculo e gordura, respectivamente.

Na Tabela 5, encontram-se os coeficientes de correlação (r) obtidos entre as principais características da carcaça. O PCF, o comprimento e a compacidade da carcaça correlacionaram-se positivamente, o que se assemelha ao resultado obtido por OLIVEIRA et al. (1998), os quais verificaram correlação entre PCF e compacidade da carcaça de $0,73(\mathrm{P}<0,01)$.

A medida de comprimento de perna apresentou correlação negativa $(\mathrm{P}<0,05)$ com a proporção de osso total na carcaça e positiva com a proporção de músculo total na carcaça e proporção de músculo total na costela. O perímetro de braço não apresentou boa correlação com o músculo da paleta, o que não era esperado.

A área de olho de lombo (AOL) neste estudo não apresentou correlação significativa $(\mathrm{P}<0,05)$ com o músculo total da carcaça, e sim com o comprimento da carcaça. De acordo com MÜLLER (1980), a AOL, isoladamente, não apresenta correlação alta com a proporção de músculo da carcaça, mas, se utilizada em conjunto com outros parâmetros, auxilia na avaliação do grau de rendimento em cortes desossados.

As correlações da proporção de músculo da carcaça (MC), com as proporções de músculo da costela, paleta e quarto, foram 0,$85 ; 0,77$; e 0,67 , respectivamente. Estes resultados estão em desacordo com os verificados por LATHAM et al. (1964), os quais observaram o melhor coeficiente de correlação entre músculo da carcaça e da paleta, e KHANDEKAR et al. (1965), que obtiveram 0,99 
Tabela 3 - Relações entre os tecidos da carcaça Table 3 - Relationships among the carcass tissues

\begin{tabular}{lccccccc}
\hline $\mathrm{PA}(S W) \mathrm{kg}$ & $\mathrm{PN}(B W)$ & $\mathrm{PD}(W W)$ & $\mathrm{P}_{28}\left(W_{28}\right)$ & $\mathrm{P}_{33}\left(W_{33}\right)$ & $\mathrm{F}$ & $\mathrm{Pr}>\mathrm{F}$ & $\mathrm{CV} \%$ \\
\cline { 2 - 6 } & 4,12 & 20,93 & 28,30 & 32,57 & & & \\
\cline { 2 - 6 } PCF $(C C W) \mathrm{kg}$ & 1,72 & 10,71 & 12,79 & 13,75 & & & \\
\hline M/O $(M / B)$ & $1,74^{\mathrm{b}}$ & $3,10^{\mathrm{a}}$ & $3,14^{\mathrm{a}}$ & $3,42^{\mathrm{a}}$ & 11,07 & 0,0002 & 16,12 \\
M/A $(M / A)$ & - & $2,95^{\mathrm{b}}$ & $3,43^{\mathrm{ab}}$ & $4,66^{\mathrm{a}}$ & 2,46 & 0,1194 & 37,48 \\
TM/O $(S T / B)$ & $1,74^{\mathrm{b}}$ & $4,20^{\mathrm{a}}$ & $4,13^{\mathrm{a}}$ & $4,24^{\mathrm{a}}$ & 19,15 & 0,0001 & 15,61 \\
\hline
\end{tabular}

Médias, na linha, seguidas por letras distintas, diferem $(\mathrm{P}<0,05)$ pelo teste $\mathrm{Pdiff}$.

$\mathrm{PA}=$ Peso de abate; $\mathrm{PCF}=$ Peso de carcaça fria; $\mathrm{M} / \mathrm{O}=$ Tecido muscular/ossos; $\mathrm{M} / \mathrm{A}=$ Tecido muscular/ adiposo; $\mathrm{TM} / \mathrm{O}=$ Tecido mole (tecido muscular + adiposo) $/$ ossos $; \mathrm{PN}=$ Peso ao nascimento, $\mathrm{PD}=$ Peso ao desmame $; \mathrm{P}_{28}=\mathrm{Peso}$ ao abate de $28 \mathrm{~kg} ; \mathrm{P}_{33}=$ Peso ao abate de $33 \mathrm{~kg}$.

Means, within a row, followed by different letters are different $(P<.05)$ by $P$ diff test.

$S W=$ Slaughter weight $: C C W=$ Cold carcass weight $M / B=$ Muscles/bone; $M / A=$ Muscles/adipose tissue; $S T / B=$ Soft tissue (muscles + adipose tissue)/bone; $B W=$ Birth weight; $W W=$ Weaning weight; $W_{28}=$ Slaughter weight of $28 \mathrm{~kg} ; W_{33}=$ Slaughter weight of $33 \mathrm{~kg}$.

Tabela 4 - Equações de regressão da composição tecidual da carcaça

Table 4 - Regression equations of the carcass tissue composition

\begin{tabular}{|c|c|c|}
\hline $\begin{array}{l}\text { Parâmetros } \\
\text { Parameters }\end{array}$ & $\begin{array}{l}\text { Equações } \\
\text { Equations }\end{array}$ & $\mathrm{R}^{2}$ \\
\hline \multicolumn{3}{|l|}{ Osso $(\mathrm{O})$} \\
\hline \multicolumn{3}{|l|}{ Bone (B) } \\
\hline $\begin{array}{l}\% \text { Osso no quarto }(\mathrm{OQ}) \\
\% \text { Hindquarter bone }(H B)\end{array}$ & $\mathrm{O}(B)=16,083612+0,188999 . \mathrm{OQ}(\mathrm{HB})$ & 2,00 \\
\hline $\begin{array}{l}\% \text { Osso na paleta }(\mathrm{OP}) \\
\% \text { Shoulder bone }(S B)\end{array}$ & $\mathrm{O}(B)=32,221424-0,634792 . \mathrm{OP}(\mathrm{SB})$ & 8,23 \\
\hline $\begin{array}{l}\text { \% Osso na costela }(\mathrm{OC}) \\
\text { \% Rib bone }(R B)\end{array}$ & $\mathrm{O}(B)=16,058481+0,228917 . \mathrm{OC}(\mathrm{RB})$ & 93,16 \\
\hline \multicolumn{3}{|l|}{ Músculo (M) } \\
\hline $\begin{array}{l}\text { Muscle }(M) \\
\text { \%Músculo no quarto (MQ) } \\
\text { \% Hindquarter muscle (HM) }\end{array}$ & $\mathrm{M}=2,718921+0,826416 . \mathrm{MQ}(H M)$ & 44,92 \\
\hline $\begin{array}{l}\text { \% Músculo na paleta (MP) } \\
\text { \% Shoulder muscle (SM) }\end{array}$ & $\mathrm{M}=13,512472+0,746082 \cdot \mathrm{MP}(S M)$ & 59,01 \\
\hline $\begin{array}{l}\text { \% Músculo na costela (MC) } \\
\% \text { Rib muscle (RM) }\end{array}$ & $\mathrm{M}=46,846616+0,285046 \cdot \mathrm{MC}(R M)$ & 71,65 \\
\hline \multicolumn{3}{|l|}{ Gordura $(\mathrm{G})$} \\
\hline $\begin{array}{l}\text { Fat }(F) \\
\% \text { Gordura no quarto (GQ) } \\
\% \text { Hindquarter fat }(H F)\end{array}$ & $\mathrm{G}(F)=4,095696+1,374688 . \mathrm{GQ}(H F)$ & 52,24 \\
\hline $\begin{array}{l}\text { \% Gordura na paleta }(\mathrm{GP}) \\
\% \text { Shoulder fat }(S F)\end{array}$ & $\mathrm{G}(\mathrm{F})=4,742186+0,893376 . \mathrm{GP}(S F)$ & 76,31 \\
\hline $\begin{array}{l}\text { \% Gordura na costela (GC) } \\
\% \text { Rib fat }(R F)\end{array}$ & $\mathrm{G}(F)=4,535684+0,425720 . \mathrm{GC}(R F)$ & 79,89 \\
\hline
\end{tabular}


Rev. bras. zootec.

Tabela 5 - Coeficientes de correlação

Table 5 - Coefficients of correlation

\begin{tabular}{|c|c|c|c|c|c|c|c|c|}
\hline & $\begin{array}{l}\text { PCF } \\
C C W\end{array}$ & $\begin{array}{l}C C \\
C L\end{array}$ & $\begin{array}{l}\mathrm{OC} \\
C B\end{array}$ & $\begin{array}{l}\mathrm{MC} \\
C M\end{array}$ & $\begin{array}{l}\mathrm{GC} \\
C F\end{array}$ & $\begin{array}{l}\text { MQ } \\
H M\end{array}$ & $\begin{array}{l}\text { MP } \\
S M\end{array}$ & $\begin{array}{c}\text { MCO } \\
R M\end{array}$ \\
\hline $\mathrm{CC}(C L)$ & $0,89^{* *}$ & & $-0,17^{\mathrm{ns}}$ & $0,39^{\text {ns }}$ & $-0,27^{\mathrm{ns}}$ & $0,35^{\mathrm{ns}}$ & $0,33^{\text {ns }}$ & $0,45^{\mathrm{ns}}$ \\
\hline $\mathrm{CP}(L L)$ & $0,57^{*}$ & $0,59^{* *}$ & $-0,58^{*}$ & $0,51^{*}$ & $-0,14^{\mathrm{ns}}$ & $0,41^{\mathrm{ns}}$ & $0,27^{\mathrm{ns}}$ & $0,60^{* *}$ \\
\hline $\mathrm{LP}(L W)$ & $0,60^{* *}$ & $0,64^{* *}$ & $-0,28^{\mathrm{ns}}$ & $0,48^{*}$ & $-0,41^{\mathrm{ns}}$ & $0,71 * *$ & $0,45^{\mathrm{ns}}$ & $0,50^{*}$ \\
\hline $\operatorname{PBR}(A P)$ & $0,68^{* *}$ & $0,58^{*}$ & $-0,008^{\mathrm{ns}}$ & $-0,14^{\mathrm{ns}}$ & $0,15^{\mathrm{ns}}$ & $0,05^{\mathrm{ns}}$ & $-0,30^{\mathrm{ns}}$ & $0,07^{\mathrm{ns}}$ \\
\hline $\mathrm{EG}(F T)$ & $-0,13^{\text {ns }}$ & $-0,43^{\mathrm{ns}}$ & $-0,25^{\mathrm{ns}}$ & $-0,45^{\mathrm{ns}}$ & $0,63^{* *}$ & $-0,51^{*}$ & $-0,66 * *$ & $-0,14^{\mathrm{ns}}$ \\
\hline $\operatorname{COM}(L W / C L)$ & $0,88^{* *}$ & $0,58^{*}$ & $-0,54^{*}$ & $0,35^{\mathrm{ns}}$ & $0,009^{\mathrm{ns}}$ & $0,13^{\mathrm{ns}}$ & $0,01^{\mathrm{ns}}$ & $0,57^{*}$ \\
\hline $\operatorname{AOL}(L E A)$ & $0,37^{\mathrm{ns}}$ & $0,51 *$ & $0,05^{\mathrm{ns}}$ & $0,32^{\mathrm{ns}}$ & $-0,35^{\mathrm{ns}}$ & $0,34^{\mathrm{ns}}$ & $0,18^{\mathrm{ns}}$ & $0,17^{\mathrm{ns}}$ \\
\hline $\mathrm{OC}(C B)$ & $-0,39^{\mathrm{ns}}$ & & & $-0,37^{\mathrm{ns}}$ & $-0,26^{\mathrm{ns}}$ & $-0,23^{\mathrm{ns}}$ & $0,11^{\mathrm{ns}}$ & $-0,67^{* *}$ \\
\hline $\mathrm{MC}(C M)$ & $0,42^{\mathrm{ns}}$ & & & & $-0,77^{* *}$ & $0,67^{* *}$ & $0,77^{* *}$ & $0,85^{* *}$ \\
\hline $\mathrm{GC}(C F)$ & $-0,15^{\mathrm{ns}}$ & & & & & $-0,65^{*}$ & $-0,90 * *$ & $-0,45^{\mathrm{ns}}$ \\
\hline MQ (HM) & $0,28^{\mathrm{ns}}$ & & & & & & $0,63^{*}$ & $0,57^{*}$ \\
\hline $\mathrm{MP}(S M)$ & $0,19^{\mathrm{ns}}$ & & & & & & & $0,47^{*}$ \\
\hline $\operatorname{MCO}(R M)$ & $0,57^{*}$ & & & & & & & \\
\hline
\end{tabular}

${ }^{* *} \mathrm{P}<0,01 ;{ }^{*} \mathrm{P}<0,05 ;$ ns não-significativo (not significant).

$\mathrm{PCF}=$ Peso de carcaça fria; $\mathrm{CC}=$ Comprimento de carcaça; $\mathrm{CP}=$ Comprimento de perna; $\mathrm{LP}=\mathrm{Largura}$ de perna; $\mathrm{PBR}=\mathrm{Perímetro} \mathrm{de} \mathrm{braço;} \mathrm{EG}$ = Espessura de gordura; $\mathrm{COM}=$ Compacidade da carcaça; $\mathrm{AOL}=$ Area de olho de lombo; $\mathrm{OC}=\mathrm{Osso}$ total da carcaça; $\mathrm{MC}=\mathrm{Músculo}$ total da carcaça; $\mathrm{GC}=$ Gordura total da carcaça; $\mathrm{MQ}=$ Músculo do quarto; $\mathrm{MP}=$ Músculo da paleta; $\mathrm{MCO}=\mathrm{Músculo} \mathrm{da} \mathrm{costela.}$

$C C W=$ Cold carcass weight; $C L=$ Carcass lenght; $L L=$ Leg lenght; $L W=$ Leg width; $A P=$ Arm perimeter; $F T=$ Fat thickness; $L W(L$ ive weight)/CL (carcass lenght); $L E A=$ longissimus muscle area; $C B=$ Carcass bone; $C M=$ Carcass muscle; $C F=$ Carcass fat HM = Hindquarter muscle; $S M=S h o u l d e r$ muscle; $R M=R i b$ muscle.

como coeficiente de correlação entre o músculo do quarto e a proporção total de músculo da carcaça. No entanto, os resultados são semelhantes aos observados por CARVALHO et al. (1998), os quais verificaram que a proporção de músculo da costela foi a variável que melhor representou a composição total da mesma $(r=0,85)$, seguida pela paleta $(r=0,79)$ e pelo quarto $(\mathrm{r}=0,77)$.

\section{Conclusões}

O abate de cordeiros ao desmame com 45 dias de idade e peso aproximado de $20 \mathrm{~kg}$ proporcionou altos rendimentos de carcaça, no entanto, o abate aos $28 \mathrm{~kg}$ de peso vivo é o mais adequado, pois proporciona maior equilíbrio quanto às características quantitativas da carcaça.

A costela é o corte que melhor expressa as proporções de osso, músculo e gordura da carcaça.

\section{Referências Bibliográficas}

BERG, R.T., BUTTERFIELD, R.M. 1976. New concepts of cattle growth. Sydney: Sydney University Press. 240p.

BUENO, M.S., CUNHA, E.A., SANTOS, L.E. et al. Desempenho e características de carcaças de cordeiros Suffolk alimentados com diferentes tipos de volumosos. In: REUNIÃO ANUAL DA SOCIEDADE BRASILEIRA DE ZOOTECNIA, 35, 1998, Botucatu. Anais ...Botucatu: SBZ, 1998. p.206-208.
CARVALHO, S. Desempenho, composição corporal e exigências nutricionais de cordeiros machos inteiros, machos castrados e fêmeas alimentados em confinamento. Santa Maria, RS: UFSM, 1998. 100p. Dissertação (Mestrado em Zootecnia) - Universidade Federal de Santa Maria, 1998.

CARVALHO, S., PIRES, C.C., PERES, J.R.R. et al. Predição da composição tecidual da carcaça de cordeiros. In: REUNIÃO ANUAL DA SOCIEDADE BRASILEIRA DE ZOOTECNIA, 35, 1998, Botucatu. Anais... Botucatu: SBZ, 1998. p.110-112.

CASTAÑER, J.L.O., ASTIZ, C.S., ALFRANCA, I.S. 1992. Produccion de carne en la agrupacion ovina Churra Tensina: calidad de la canal y de la carne en los tipos ternasco y cordero de cebo. Archivos de Zootecnia, 41(153):197-208.

CHIOU, P.W.S., JORDAN, R.M. 1973. Ewe milk replacer diets for young lambs. III. Effect of age os lambs and dietary protein and fat levels on the body composition of young lambs. J. Anim. Sci., 36(3):607-611.

GARCIA, C.A., SOBRINHO, A.G.S. Desempenho e características das carcaças de ovinos alimentados com resíduo de panificação "biscoito". In: REUNIÃO ANUAL DA SOCIEDADE BRASILEIRA DE ZOOTECNIA, 35, 1998, Botucatu. Anais ... Botucatu: SBZ, 1998. p.29-31.

GARCIA, I.F.F., PÉREZ, J.R.O., KEMENES, P.A. et al. Características de carcaça de cordeiros Santa Inês com dieta contendo pedúnculo de caju. In: REUNIÃO ANUAL DA SOCIEDADE BRASILEIRA DE ZOOTECNIA, 35, 1998 , Botucatu. Anais ...Botucatu: SBZ, 1998. p.185-187.

JORGE, A.M., FONTES, C.A.A., PAULINO, M.F. et al. 1999. Desempenho produtivo de animais de quatro raças zebuínas abatidos em três estádios de maturidade. 2. Características da carcaça. Rev. bras. zootec., 28(2):381-387.

KHANDEKAR, V.N., GOLDSTONE, C.L., McMANUS, W.R. 1965. Some indices on the carcass composition of Dorset Horn top cross lambs. 1. Measurements on the live body and carcass, 
the composition of sample foents and their relationship to carcass composition. J. Agric. Sci., 65(2):147-154.

LATHAN, S.D., MOODY, U., KEMP, J.D. et al. 1964. Reliability of predicting lamb carcass composition. J. Anim. Sci., 23:861-866.

MONTEIRO, A.L.G., GARCIA, C.A., NEVES, M.A. et al. Efeito da substituição do milho pela polpa cítrica no desempenho e características das carcaças de cordeiros confinados In: REUNIÃO ANUAL DA SOCIEDADE BRASILEIRA DE ZOOTECNIA, 35, 1998, Botucatu. Anais... Botucatu: SBZ, 1998. p.95-100.

MÜLLER, L. 1980. Normas para avaliação de carcaças e concurso de carcaças de novilhos. Santa Maria: Imprensa Universitária/UFSM. 31p.

NATIONAL RESEARCH COUNCIL - NRC. 1985. Nutrient requirements of sheep. 6.ed. Washington: National Academy Press. 99p.

OLIVEIRA, N.M., OSÓRIO, J.C.S., VILLARROEL, A.S. 1998. Produção de carne em ovinos de cinco genótipos. 5. Estimativas de qualidade e peso de carcaça através do peso vivo. Ciência Rural, 28(4):665-669.

OSÓRIO, J.C., OLIVEIRA, N.M., NUNES, A.P. et al. 1996. Produção de carne em ovinos de cinco genótipos. 3. Perdas e morfologia. Ciência Rural, 26(3):447-481.

OSÓRIO, J.C.S., ASTIZ, C.S., OSÓRIO, M.T.M. et al. 1998. Produção de carne ovina: Alternativa para o Rio Grande do Sul. Pelotas: Editora Universitária/UFPEL. 166p.

OSÓRIO, J.C., JARDIM, P.O.C., PIMENTEL, M.A. et al. 1999. Produção de carne entre cordeiros castrados e não castrados. 1 - Cruzas Hampshire Down x Corriedale. Ciência Rural, 29(1):135-138.

PÉREZ, J.R.O., GARCIA, I.F.F., TEIXEIRA, J.C. et al. Características de carcaça de cordeiros Santa Inês e Bergamácia com diferentes níveis de dejetos de suínos na dieta. In: REUNIÃO ANUAL DA SOCIEDADE BRASILEIRA DE ZOOTECNIA, 35, 1998, Botucatu. Anais ... Botucatu: SBZ, 1998. p.176-178.
PIRES, C.C., ARAÚJO, J.R., BERNARDES. R.A.C. et al. 1999 Desempenho e características da carcaça de cordeiros de três grupos genéticos abatidos ao mesmo estágio de maturidade. Ciência Rural, 29(1):155-158.

SAS INSTITUTE. 1990. SAS User's guide: statistics, Cary/ North Carolina, v.2, version 6, 4.ed.

SILVA, J.S., SALVADO, A.L., PORTUGAL, A.V. 1994. Estudo do crescimento e da composição das carcaças de borregos da raça Churra da terra quente. $R$. Portug. Zootec., 1(2):127-136.

SILVA, L.F. Crescimento, composição corporal e exigências nutricionais de cordeiros abatidos com diferentes pesos. Santa Maria, RS: UFSM, 1999. 64p. Dissertação (Mestrado em Zootecnia) - Universidade Federal de Santa Maria, 1999.

SIQUEIRA, E.R., FERNADES, S. 1999. Pesos, rendimentos e perdas da carcaça de cordeiros Corriedale e mestiços Ile de France x Corriedale, terminados em confinamento. Ciência Rural, 29(1):143-148.

WYNN, P.C., THWAITES, C.J. 1981. The relative growth and development of the carcass tissues of merino and crossbred rams and wethers. Aust. J. Agric. Res., 32:947-956.

Recebido em: 01/07/1999

Aceito em: 21/02/2000 